\section{Moments of insight}

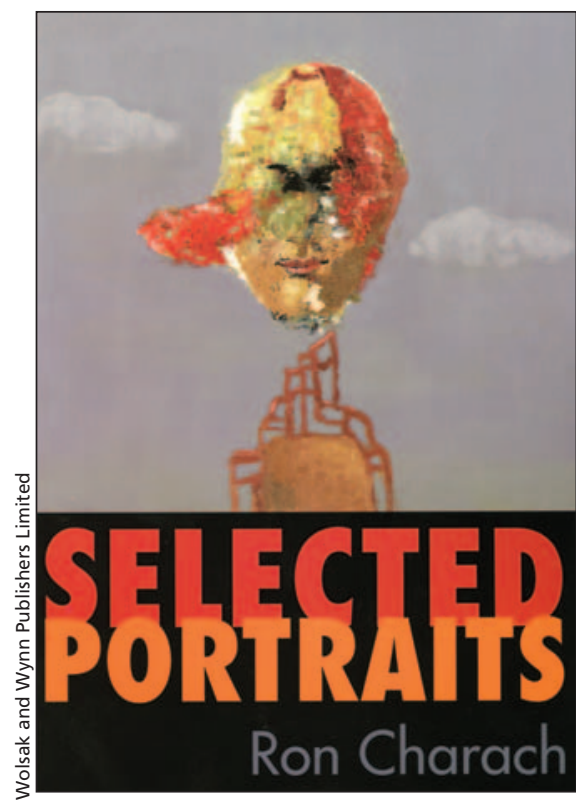

Selected Portraits

Ron Charach MD

Wolsak and Wynn Publishers Limited; 2007 128 pp \$17 ISBN 978-1-894987-20-2

I n his Selected Portraits, Dr. Ron Charach presents a reprise of his poetic renderings - as son, friend, husband, father, physician and psychiatrist - and reveals aspects of his ongoing self-discovery and attentive interest in the lives of others. The reader thus encounters moments of insight and delight, and moments of puzzlement and heartache: each authentic, each affecting and each inviting self-reflection. As I read Charach's poems aloud and "listen" to myself responding, my own "moments" present themselves and new meanings emerge. So rather than offering you a review of Charach's book I will use a few selections to illustrate my own process of thematic engagement and encourage you to seek your own. In Waterlines, Charach is a loving dad.

\section{Holding my baby daughter as she squirms and chortles in the chest-high water of the sheltered bay, her softness against me, nothing is but the soft slap of waves and a fade of others playing -}

My mouth opens with a smile, and with anticipation, warm memories flood: my daughters, now adult, with whom I once enjoyed such delicious moments.

Whilst driving back to the city, the father watches in the mirror, my darling little charge, somberly resigning himself to being unable to protect his treasured child "against what lurks / in the long cold waters of life ahead. I think sadly of what my girls have faced, am proud of their courage and ashamed of only sometimes being able to offer them only a towel. They offer far more to their own charges.

Desperate is the plight of the child in Failure to Thrive, who faces the devastating impact of parental neglect and abandonment.

If only there were but one way to fail, a hapless baby or two lacking the know-how to suck, breathe and swallow at the same time.

This hapless baby is born of and to ...this progeny of souls / who received no lovel so can give none...leaving the child...pulled so early / from the promised land of infancy. How do I fail thee, my charges? Let me count the ways.... "I'm sorry" scarcely matters.

In The Garden of My Wife the husband pleasures in the beauty of his lady's garden:

\section{My wife wraps her long fingers with ferns}

and tickles me with astilbe.

She cloaks the ground in periwinkle and seamless green-white lamium.

Enchanting descriptions of the fertile complexity and variance his lady presents to him lead this reluctant oriental onion to ask himself: What have I added? There was 1 treasured thing that only he could have given her and he didn't. He has deprived his love, his wife. My burdensome shame, to have done so again and again ... wife after wife...

I also considered, "Have You Seen This Man? Missing since June, 2007.”
Overnight, outside my office on the street the signs mushroom in large block letters the word "REWARD", with "offered by family" neatly penned in

above a color photo of a man too vibrant to stay in focus.

In red, his name "Dr. Michael

Wineberg,

psychiatrist, age $37 . " .$.

Feared at risk of suicide."

Ice water engulfs me. I saw these signs outside my office. Charach's is right above me.

Mornings later, the dreaded obituary mentions patients and the homeless

To whom the doctor was especially kind

Nooooo! The doctor's dead. Where were those who might have helped him? There are 6 of us in this very building! It's suddenly 1997. I am "away" adrift without purpose in Bergen-Belsen. I call home to where, deservedly, I live alone. A message from a daughter: "Daddy, please don't kill yourself while you're away." Another: "You have to get help, Dad. " ... drawn from the ice flow, held in the arms of my darling little charges and now on my way to the care of a colleague.

Yes, I conclude, these are poems well worth reading aloud - and listening to your own response.

\section{Paul Finnegan MD}

Psychiatrist/psychoanalyst Toronto, Ont.

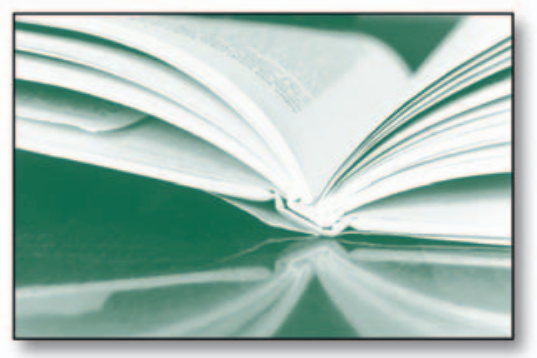

